Rio de Janeiro. Ano 11. Volume 18. Número 3. Setembro a Dezembro de 2017

Periódico Quadrimestral da Pós-Graduação Stricto Sensu em Direito Processual da UERJ

Patrono: José Carlos Barbosa Moreira. ISSN 1982-7636. pp. 69-93

www.redp.uerj.br

\title{
A (IM)POSSIBILIDADE DA (AUTO)COMPOSIÇÃO EM CONFLITOS ENVOLVENDO A ADMINISTRAÇÃO PÚBLICA: DO CONFLITO À POSIÇÃO DO TERCEIRO ${ }^{1}$
}

THE (IM)POSSIBILITY OF (SELF)COMPOSITION IN CONFLICTS INVOLVING THE PUBLIC ADMINISTRATION: FROM THE CONFLICT TO THE POSITION OF THIRD PARTY

Fabiana Marion Spengler

Pós-doutora em Direito pela Università degli Studi di Roma Tre, em Roma, na Itália, com bolsa CNPq (PDE). Doutora em Direito pelo programa de Pós-Graduação stricto sensu da Universidade do Vale do Rio dos Sinos - UNISINOS - RS, com bolsa Capes; mestre em Desenvolvimento Regional, com concentração na área Político Institucional da Universidade de Santa Cruz do Sul - UNISC - RS, docente dos cursos de Graduação e Pós Graduação lato e stricto sensu da UNISC, líder do Grupo de Pesquisa "Políticas Públicas no Tratamento dos Conflitos" vinculado ao CNPq; coordenadora e mediadora do projeto de extensão: “A crise da jurisdição e a cultura da paz: a mediação como meio democrático, autônomo e consensuado de tratar conflitos" financiado pela Universidade de Santa Cruz do Sul - UNISC; e-mail: fabiana@unisc.br. Santa Cruz do Sul, RS, Brasil.

Helena Pacheco Wrasse Mestranda do Programa de Pós-Graduação em Direito Mestrado e Doutorado - da Universidade de Santa Cruz do Sul - UNISC. Bolsista do Programa BIPSS - Bolsas

\footnotetext{
${ }^{1}$ Artigo recebido em 08/10/2017 e aprovado em 23/11/2017.
} 
Revista Eletrônica de Direito Processual - REDP.

Rio de Janeiro. Ano 11. Volume 18. Número 3. Setembro a Dezembro de 2017

Periódico Quadrimestral da Pós-Graduação Stricto Sensu em Direito Processual da UERJ

Patrono: José Carlos Barbosa Moreira. ISSN 1982-7636. pp. 69-93

www.redp.uerj.br

Institucionais para Programas de Pós-Graduação da
Universidade de Santa Cruz do Sul, RS, Edital 01/2017.
Integrante do Grupo de Pesquisas "Políticas Públicas no
tratamento dos conflitos", vinculado ao CNPq, sob a
coordenação da Prof. a Pós-Dr. a Fabiana Marion Spengler.
Advogada. E-mail: hphelenapacheco@gmail.com. Santa
Cruz do Sul, RS, Brasil.

RESUMO: O artigo versa sobre a (auto)composição em conflitos envolvendo a Administração Pública e o particular, com base no Código de Processo Civil e na Lei n. 13.140/2015. Trata-se de uma dinâmica complexa que se intende abordar, de forma reflexiva, a partir da problemática de qual terminologia seria a adequada (composição ou autocomposição) para abordar a modalidade de tratamento consensual de conflitos, quando for parte o ente estatal e por quê. Objetiva-se analisar o significado de composição, autocomposição e heterocomposição. O método de abordagem é o dedutivo, o de procedimento é o monográfico e a técnica de pesquisa é a bibliográfica.

PALAVRAS-CHAVE: Administração Pública; Autocomposição; Composição; Conflito; Heterocomposição.

ABSTRACT: The article deals with the auto-composition in conflicts involving Governing Administrations and individuals, based on the Civil Code and the Law n. 13,140 / 2015. This paper intends to reflect on this complex and dynamic issue, asking both which terminology would be the appropriate one (composition or auto-composition) to approach a method of consensual treatment of conflicts, when the governing entity is part of the conflict and why. The aim is to analyze the meaning of composition, autocomposition and hetero-composition. The method of approach is deductive, the procedural method is monographic and the research technique is bibliographic.

KEYWORDS: Governing Administration, selfcomposition, hetero-composition, composition, conflict. 


\section{INTRODUÇÃO}

O Estado é decorrente de um pacto realizado entre os homens, é fruto do contrato social e ficção jurídica proveniente da razão humana. Dentre suas atribuições estão a organização social, política e econômica de um determinado povo, que ocupa um espaço geográfico limitado. Apresenta-se como soberano e exerce seu poder e autoridade sobre seus súditos no seu território. Enquanto isso, para conseguir organizar as relações sociais, o Estado passou a criar instituições, sendo composto por uma série de órgãos, fundações, autarquias, dentre outras estruturas que auxiliam na administração pública.

Nesse sentido, o Estado pode assumir diferentes representações desde a ficção racional humana criada para gerir a sociedade à composição de diferentes instituições e estruturas que auxiliam na organização da administração pública. Dentre essas estruturas, está o Poder Judiciário - encarregado de resolver os conflitos sociais. Além dessa percepção, como entidade designada para regular as situações conflitivas, trabalha-se na ótica do Estado como litigante, como parte componente de um conflito, seja na esfera jurídica ou administrativa. Nota-se que os homens o instituem para regulamentar e organizar as suas relações e, ao mesmo tempo, conflitam com ele.

Como temática, apresenta-se a (auto)composição em conflitos envolvendo o Estado (Administração Pública) e o particular, partindo-se de análises do Código de Processo Civil $^{2}$ e da Lei n. 13.140/2015. Trata-se de uma dinâmica complexa que se intende abordar, neste artigo, de forma reflexiva, a partir da problemática: qual é a terminologia adequada (composição ou autocomposição) para se dirigir à modalidade de tratamento consensual de conflitos quando for parte o ente estatal? Por quê?

É possível a utilização dos meios consensuais de tratamento de conflitos, pois são instrumentos capazes de apresentar uma resposta adequada às controvérsias envolvendo o Estado. Todavia, a fim de aprimorar a técnica jurídica e o desenvolvimento adequado do tratamento consensual desse tipo de conflitos, é relevante o estudo acerca do gênero e espécies que envolvem os métodos consensuais. Assim, tem-se por objetivo realizar uma

\footnotetext{
${ }^{2}$ Doravante CPC.
} 
Revista Eletrônica de Direito Processual - REDP.

Rio de Janeiro. Ano 11. Volume 18. Número 3. Setembro a Dezembro de 2017

Periódico Quadrimestral da Pós-Graduação Stricto Sensu em Direito Processual da UERJ

Patrono: José Carlos Barbosa Moreira. ISSN 1982-7636. pp. 69-93

www.redp.uerj.br

análise técnica acerca do que consiste a composição, a autocomposição e a heterocomposição, bem como traçar alguns comentários acerca da Lei n. 13.140/2015 e da terminologia empregada nos artigos que versam sobre a (auto)composição na administração pública. Dentre os principais resultados busca-se responder à problemática apresentada, referindo qual a maneira adequada de se aludir à resolução consensual da dinâmica conflitiva entre Estado e particular.

O método de abordagem é o dedutivo, pois consiste na análise de categorias gerais com o fito de se atingir uma particularidade. No decorrer do texto, trabalha-se com ordens fundamentais, como a questão da legitimidade estatal, da composição, heterocomposição e autocomposição, tudo isso com o propósito de responder, no caso específico de uma relação de conflito, qual a terminologia tecnicamente mais apropriada. Como método de procedimento utiliza-se o monográfico e como técnica de pesquisa a bibliográfica, através da consulta em leis, artigos científicos e livros.

\section{O CONFLITO ENQUANTO ELEMENTO ESTRUTURAL DAS RELAÇÕES SOCIAIS E O PAPEL ESTATAL}

O homem está no mundo, contudo, passa a ser reconhecido como um ser social quando é percebido pelo outro. Um pode representar transtorno e perturbação no espaço de tranquilidade do outro. Sob essa perspectiva, percebe-se o receio em relação às ideias, aos costumes, aos interesses a às ambições que uma pessoa pode ter para com a outra ${ }^{3}$. Nesse sentido, Rene Girard ${ }^{4}$ reflete que os comportamentos humanos são aprendidos através da imitação, significando que desejos em comum e interesses semelhantes podem ensejar na rivalidade, no conflito, na adversidade, diferentemente do que defendem alguns autores que percebem, nos comportamentos miméticos, a harmonia.

Nota-se o conflito como o confronto de desejos em que se tenta ceder a resistência imposta, sendo composto por pelo menos duas forças que tentam subjugar uma a outra. A cobiça pelo mesmo objeto é um agente desencadeador do conflito, e, intimamente relacionada com a ideia de posse, está a disputa pelo poder, pois o poder sobre os objetos

\footnotetext{
${ }^{3}$ MULLER, Jean-Marie. O princípio da não-violência: percurso filosófico. Tradução de Maria Fernanda Oliveira. Lisboa: Instituto Piaget: 1995.

${ }^{4}$ GIRARD, Rene. Literatura, mimesis y antropologia. Barcelona: Gedisa, 1997.
} 
Revista Eletrônica de Direito Processual - REDP.

Rio de Janeiro. Ano 11. Volume 18. Número 3. Setembro a Dezembro de 2017

Periódico Quadrimestral da Pós-Graduação Stricto Sensu em Direito Processual da UERJ

Patrono: José Carlos Barbosa Moreira. ISSN 1982-7636. pp. 69-93

www.redp.uerj.br

gera um poder sobre os outros. Entende-se que há necessidade de dispor de certos objetos, essenciais à sobrevivência, devendo-se ter cuidado quando a busca pelo poder ultrapassa o limite, não mais sendo usada como meio de evitar a submissão aos outros, mas sim, de submeter os outros ao seu poder ${ }^{5}$.

De acordo com Jean-Marie Muller “ “o indivíduo não pode fugir a uma situação de conflito sem renunciar aos seus próprios direitos", devendo aceitar essa relação, pois através dela será reconhecido pelo outro. Assim, quando se está em combate, é interessante destacar que o resultado depende dos meios e da forma empregados para tratar o conflito, pois este pode ser destrutivo ou construtivo, dependendo daquilo que se cria a partir dele. Nesse passo, a função do conflito seria a de estabelecer um pacto entre os adversários, satisfazendo os interesses de ambos com a finalidade de construir relações de justiça, atuando como elemento estrutural das relações entre indivíduos e, consequentemente, da vida social $^{7}$.

A violência pode ocorrer de forma direta ou indireta. Quando indireta, ela é gerada por estruturas políticas, econômicas ou sociais que oprimem e alienam, sendo chamada de violência estrutural. Esse tipo de violência pode provocar injustiças que atentam contra a humanidade e a liberdade, fazendo pender sobre suas vítimas um real sentimento de morte. O injustiçado procura legitimar sua violência por assim o ser, reivindicando o seu reconhecimento e a sua identidade, através da violência da revolta (violência direta). Ocorre que legitimar a violência fará com que todos a usem sempre que seus direitos forem ameaçados, tornando-a uma fatalidade, criando-se uma cadeia de violências de difícil interrupção. A ideologia da violência permite que cada um justifique a sua própria violência ${ }^{8}$.

Por outro lado, a "não-violência", que condena e combate à violência opressora, não quer dizer um mundo sem conflitos, o autor constrói sua proposta em relações baseadas na confiança e na proximidade, salientando que a organização da vida social está

\footnotetext{
${ }^{5}$ MULLER, Jean-Marie. O princípio da não-violência: percurso filosófico. Tradução de Maria Fernanda Oliveira. Lisboa: Instituto Piaget: 1995.

${ }^{6}$ Ibidem, p. 18.

7 “Qualquer situação política é conflituosa, quanto mais não seja de forma potencial. A coexistência entre os homens e os povos deve tornar-se pacífica, mas permanecerá sempre conflituosa. A paz não é, não pode ser nem nunca será a ausência de conflitos, mas o domínio, a gestão e a resolução dos conflitos por meios diferentes da violência destruidora e mortífera. A acção [sic] política também deve procurar a resolução (do latim resolutio, acção de desatar) não-violenta dos conflitos” (Ibidem, grifado no original, p. 19).

${ }^{8}$ Idem.
} 
Revista Eletrônica de Direito Processual - REDP.

Rio de Janeiro. Ano 11. Volume 18. Número 3. Setembro a Dezembro de 2017

Periódico Quadrimestral da Pós-Graduação Stricto Sensu em Direito Processual da UERJ

Patrono: José Carlos Barbosa Moreira. ISSN 1982-7636. pp. 69-93

www.redp.uerj.br

baseada na justiça. A ação política visa organizar a justiça entre os que estão longe, implicando na criação de leis e instituições que regulem o conflito - o qual pode acontecer a qualquer momento. O conflito integra a natureza humana, é "criado para ser ultrapassado", devendo as pessoas se comprometerem no estabelecimento de relações pacíficas, despidas de medos e ameaças.

Diante dessas reflexões, compreende-se que a sociedade é composta por pessoas diferentes que enfrentarão situações conflituosas e que isso é inevitável. As diferenças são constatadas no sentido de que nem todos possuem as mesmas oportunidades, que essas não são ofertadas de forma equitativa, não se reconhece uma sociedade na qual os homens gozem dos mesmos privilégios. Defendia Aristóteles ${ }^{10}$ que o Estado não seria formado por semelhantes, pois se todos fossem iguais "poderia haver dunas de areia humanas ou outras formações moleculares engendradas pelos elementos, mas não haveria estrutura, em sentido, nem progresso" $" 11$.

A sociedade é imprescindível, uma vez que, pessoas diferentes criam instituições comuns a fim de manter a sua sobrevivência e possivelmente melhorar de vida. Essas diferenças são importantes na medida em que os interesses de uns complementam aos dos outros. Por outro lado, representam também, a capacidade de uns imporem a sua vontade aos demais, através da força, por exemplo. Essa distribuição desuniforme é resultado de estruturas de poder. Alguns ocupam uma posição na qual estabelecem a lei que regerá a situação dos demais ${ }^{12}$.

No decorrer da história, tem-se a monarquia, época em que pouquíssimos estabeleciam as regras sociais e o faziam praticamente sem questionamentos do povo. Existiram períodos administrados por bons e maus governantes, até que, gradualmente, mais pessoas passaram a integrar o processo legislativo, ainda que fossem uma minoria. As diferenças são de época e lugar, "um grau de democracia era a característica de certas ilhas de associação nos oceanos de dominação" ${ }^{\prime 13}$. Na medida em que o poder, que pertencia a uma minoria, foi colocado ao controle de mais pessoas e, por fim, de muitas pessoas, as

\footnotetext{
${ }^{9}$ Idem.

${ }^{10}$ ARISTÓTELES. Política: livro II. In: MORRIS, Clarence (Org.). Os grandes filósofos do Direito. São Paulo: Martins Fontes, 2002.

${ }^{11}$ DAHRENDORF, Ralf. O conflito social moderno: um ensaio sobre a política da liberdade. São Paulo: Jorge Zahar Editor, 1992, p. 40.

${ }^{12}$ Idem.

${ }^{13}$ Ibidem, p. 42.
} 
Revista Eletrônica de Direito Processual - REDP.

Rio de Janeiro. Ano 11. Volume 18. Número 3. Setembro a Dezembro de 2017

Periódico Quadrimestral da Pós-Graduação Stricto Sensu em Direito Processual da UERJ

Patrono: José Carlos Barbosa Moreira. ISSN 1982-7636. pp. 69-93

www.redp.uerj.br

desigualdades perderam seu caráter determinista e, pelo menos em princípio, as posições

sociais se tornariam alcançáveis.

Ao tratar sobre o contrato social, Ralf Dahrendorf o percebe como dinâmico e sujeito à mudança: “o homem é o ferrão que produz os antagonismos dos quais o progresso flui, incluindo mais chances de vida dentro de um contrato social aperfeiçoado"14. Assim, tem-se que o "poder gera não apenas a desigualdade mas, pelo mesmo motivo, o conflito" $"$. O autor lança mão da teoria de classe de Marx, afirmando que a origem do conflito de classe é encontrada nas estruturas de poder, as quais não possuiriam mais a característica absoluta de hierarquia fortificada, "o assunto do conflito de classe são as chances de vida. Mais precisamente, é a distribuição desigual das chances de vida. Os que estão em desvantagem exigem daqueles que estão em posição de vantagem mais prerrogativas e provimentos". 16

A luta para satisfazer as necessidades vitais é dinâmica e acompanha o indivíduo por toda sua existência. O conflito é uma forma de relacionamento através da qual se busca romper a oposição do outro, tentando dominar e impor a sua verdade, a sua vontade. A violência não é necessariamente física e direta, ela pode se apresentar de maneira direta ou indireta, bem como se tratar de ameaça física ou de cunho psicológico, podendo desencadear na vitória de um sobre o outro - independentemente da lógica e coerência dos argumentos. Entretanto, quando é aceita a intervenção de terceiros, no sentido de tentar solucionar o problema, percebe-se não estar se referindo tão somente a um choque ou confronto de interesses, mas sim a um procedimento contencioso, no qual os envolvidos se tratam como adversários. ${ }^{17}$

Karl Marx ${ }^{18}$, em sua teoria, apresenta o Estado como o mecanismo de domínio de classes e percebe non domínio político o reflexo do conflito entre essas classes. Assim, ao tratar quais seriam as responsabilidades estatais, destaca que este viabiliza a exploração e

\footnotetext{
${ }^{14}$ Ibidem, p. 42-43.

15 Idem.

${ }^{16}$ Idem.

17 “O conflito é uma forma social possibilitadora de elaborações evolutivas e retroativas no concernente a instituições, estruturas e interações sociais, possuindo a capacidade de se construir num espaço em que o próprio confronto é um ato de reconhecimento produzindo, simultaneamente, uma transformação nas relações daí resultantes. Desse modo, o conflito pode ser classificado como um processo dinâmico de interação humana e confronto de poder no qual uma parte influencia e qualifica o movimento da outra" (SPENGLER, Fabiana Marion. Da jurisdição à mediação: por uma outra cultura no tratamento de conflitos. Ijuí: Editora Unijuí, 2010, p. 248).

${ }^{18}$ MARX, Karl. O capital. O rendimento e suas fontes. São Paulo: Nova cultura, 1996.
} 
Revista Eletrônica de Direito Processual - REDP.

Rio de Janeiro. Ano 11. Volume 18. Número 3. Setembro a Dezembro de 2017

Periódico Quadrimestral da Pós-Graduação Stricto Sensu em Direito Processual da UERJ

Patrono: José Carlos Barbosa Moreira. ISSN 1982-7636. pp. 69-93

www.redp.uerj.br

aprovisiona estabilidade, mantendo as condições sociais que permitem a permanência de um grupo no poder, defendendo os interesses da classe dominante. Ele idealizava uma sociedade comunista sem miséria ou fome, sem desigualdades, na qual haveria uma intenção social única, a produção econômica estaria atrelada a um consenso universal, dispensando-se um aparato estatal coercitivo.

Por outro lado, Max Weber ${ }^{19}$ elaborou uma teoria do conflito e suas relações com poder, trabalhando a noção entre poder legítimo e ilegítimo. Alguns possuem o mérito de serem obedecidos, ou seja, possuem autoridade, esta pode se manifestar através de uma pessoa, instituição ou até mesmo uma mensagem, o que quer dizer que existe uma identidade de opiniões entre o emissor e o receptor daquela ideia, é uma opinião acolhida com respeito, passível de ser seguida, submete-se a ela. Essa relação pode ser analisada de duas posições: daquela de quem emite a ordem e de quem a recebe.

Ainda sobre a teoria weberiana, o poder legítimo é: a) a legitimidade carismática, que considera as características do líder, cultuado por seus governados como sendo um herói; b) a tradicional, cujo alicerce é o costume, a aceitação com base no passado, pode ser o rei ou o chefe da tribo; c) e a legal/racional fundada em regras formais, a sociedade obedece às determinações codificadas, entendendo-as como fonte de autoridade. Assim, Max Weber ${ }^{20}$ define a conexão social com base na racionalidade.

Pierre Bourdieu ${ }^{21}$ alude ao poder pela linguagem destacando que as palavras e as palavras de ordem têm poder de preservação da ordem ou de sua subversão. Existe uma crença nas palavras e também naquele que as profere. Todavia, o cultivo dessa crença não é de competência das palavras ${ }^{22}$. Bourdieu pesquisa a questão do poder simbólico, subordinado, como forma transformada, transfigurada e legitimada de outras formas de poder; perpassando os modelos energéticos que propõem as relações sociais como relações de força e dos modelos cibernéticos que as tratam como relações de comunicação; a transmutação das "diferentes espécies de capital em capital simbólico" e também, o trabalho de dissimular e transfigurar, garantindo uma "transubstanciação das relações de força fazendo ignorar-reconhecer a violência que elas encerram", transformando-as em

\footnotetext{
${ }^{19}$ WEBER, Max. Economia e sociedade. Fundamentos da sociologia compreensiva. Brasília: UNB, 1999.

${ }^{20}$ Idem.

${ }^{21}$ BOURDIEU, Pierre. O poder simbólico. Rio de Janeiro: Bertrand Brasil, 2005.

${ }^{22}$ Idem.
} 
Revista Eletrônica de Direito Processual - REDP.

Rio de Janeiro. Ano 11. Volume 18. Número 3. Setembro a Dezembro de 2017

Periódico Quadrimestral da Pós-Graduação Stricto Sensu em Direito Processual da UERJ

Patrono: José Carlos Barbosa Moreira. ISSN 1982-7636. pp. 69-93

www.redp.uerj.br

poder simbólico com capacidade de produzir efeitos reais sem, aparentemente, gastar energia $^{23}$.

Ao se pensar o Estado a partir da compreensão do poder simbólico e que ele representa tem-se que o Estado é composto por agentes e instituições e exerce autoridade soberana sobre um grupo de pessoas que ocupam determinado território. Vislumbra-se o Estado como resultado de uma crença da coletividade, a qual deposita neste o poder legítimo de gerir a sociedade.

Nesse passo, apresenta-se uma duplicidade de papeis ocupados pelo Estado: este enquanto um dos polos de uma relação conflitiva e também na qualidade de gestor das relações sociais. Deve-se considerar que o Estado, quando ocupa uma postura conflitiva em relação aos seus administrados, está representando interesses que são públicos e pertencem, justamente, àquelas pessoas que o legitimam ${ }^{24}$. Ao mesmo tempo, o outro polo do conflito, possivelmente, será ocupado por um cidadão - o legitimador do poder estatal. Trata-se de uma relação social complexa, sobre a qual se pretende compreender acerca das possibilidades trazidas pelos atuais contornos legislativos, como o CPC e a Lei n. 13.140/2015, no que dizem respeito a (auto)composição em conflitos envolvendo a Administração Pública. Assim, discorre-se acerca da heterocomposição e da autocomposição com a finalidade de qualificar o movimento transacional entre cidadão e Administração Pública.

\section{A HETERO E A (AUTO)COMPOSIÇÃO ENQUANTO DIMENSÕES DE LIDAR COM OS CONFLITOS}

Os conflitos, segundo a classificação de Niceto Alcalá Zamora y Castillo, ${ }^{25}$ podem ser resolvidos por meio da autotutela, da autocomposição ou da tutela jurisdicional (ou jurisdição). Nesse sentido, entende-se a autotutela como a sobreposição de uma parte sobre a outra, ante o sacrifício do interesse de um, o outro triunfa. Para isso, lança-se mão da

\footnotetext{
${ }^{23}$ Ibidem, p. 15.

${ }^{24}$ Um dos princípios que regem a administração pública é a supremacia do interesse público, este deve ser considerado quando da transação com qualquer ente da Administração Pública que compõe o Estado e, por isso será retomado no decorrer do texto.

${ }^{25}$ Essa classificação é atribuída à Niceto Alcalá Zamora y Castillo (CASTILLO, Niceto Alcalá Zamora y. Proceso, autocomposición y autodefensa. México: Universidad Nacional Autónoma de México, 1991).
} 
Revista Eletrônica de Direito Processual - REDP.

Rio de Janeiro. Ano 11. Volume 18. Número 3. Setembro a Dezembro de 2017

Periódico Quadrimestral da Pós-Graduação Stricto Sensu em Direito Processual da UERJ

Patrono: José Carlos Barbosa Moreira. ISSN 1982-7636. pp. 69-93

www.redp.uerj.br

ameaça ou uso da força, perspicácia ou esperteza, sua aplicação remete a um conceito de sociedade primitivo, pois conduz ao descontrole e à prevalência da violência. Trata-se de formato de solução aplicado nas relações internacionais, mas no plano nacional (interno), salvo raras exceções é proibida. ${ }^{26}$

Com a organização política dos povos, o Estado cada vez mais restringiu a autotutela, reservando-se o direito de utilizar os meios adjudicatórios, mediante a aplicação da norma ao caso concreto de forma impositiva. ${ }^{27}$ Enquanto a autotutela e a autocomposição são considerados mecanismos parciais, a tutela representa uma forma imparcial por excelência, sendo materializada através do processo. Contudo, o processo e a tutela não são termos exclusivos da atividade estatal exercida pelo Poder Judiciário, pois a arbitragem, embora desconectada do Poder Judiciário e instituída na forma de compromisso, também é caracterizada pela imposição de uma decisão de um terceiro com poderes para tanto - o árbitro. Sendo assim, esses dois formatos de resolução de conflitos são chamados/qualificados como heterônomos. ${ }^{28}$

A tutela heterônoma, também conhecida pelo termo heterocomposição (hetero + composição), é um substantivo feminino que quer dizer, no Direito: “forma de resolução de conflitos em que as partes aceitam a presença de um terceiro com poder de decisão na lide" ${ }^{29}$ Existe, necessariamente, a imposição de uma decisão proferida por um terceiro (juiz ou árbitro) com a finalidade de colocar fim à demanda. A heterocomposição é a classificação da qual decorrem as subclassificações da adjudicação, ${ }^{30}$ da decisão administrativa ${ }^{31}$ e da arbitragem. ${ }^{32}$ Hetero, por sua vez, é um prefixo ou radical que na

\footnotetext{
${ }^{26}$ CALMON, Petrônio. Fundamentos da mediação e da conciliação. Brasília: Gazeta Jurídica, 2015.

${ }^{27}$ SILVA, Érica Barbosa e. Conciliação judicial. Brasília: Gazeta Jurídica, 2013.

${ }^{28}$ CALMON, Petrônio. Op. cit.

${ }^{29}$ HETEROCOMPOSIÇÃO. In: Dicionário Priberam da Língua Portuguesa, 2008-2013. Disponível em: https://www.priberam.pt/dlpo/heterocomposi\%C3\%A7\%C3\%A3o. Acesso em: 18 set. 2017.

30 A adjudicação é o sistema tradicional de justiça: o Poder Judiciário. Sendo assim, é involuntário, vinculante e a decisão pode ser alvo de recurso. Um terceiro neutro e imparcial (juiz) irá impor a sua sentença às partes litigantes. Esses atos acontecem em meio a uma estrutura formal que atende regras rígidas, havendo momentos específicos para apresentação de provas e argumentos. Ao contrário da arbitragem é um procedimento público. Ligados pelo conflito, os envolvidos esperam que o juiz lhes apresente uma solução, que declare quem têm mais direitos, ou razão, ou seja, determine um vencedor e um perdedor e, sendo assim, a responsabilidade é transferida. Nesse sentido é a leitura de GOLDBERG, B. et al. Dispute resolution: negotiation, mediation and other processes. New York: Aspen Publishers, 2007, tradução livre.

31 É uma subdivisão da heterocomposição, em alguns países a fase administrativa, por si só encerra processos/litígios, contudo, em outros lugares, como no contexto brasileiro, trata-se apenas de uma tentativa/possibilidade.
} 
Revista Eletrônica de Direito Processual - REDP.

Rio de Janeiro. Ano 11. Volume 18. Número 3. Setembro a Dezembro de 2017

Periódico Quadrimestral da Pós-Graduação Stricto Sensu em Direito Processual da UERJ Patrono: José Carlos Barbosa Moreira. ISSN 1982-7636. pp. 69-93

www.redp.uerj.br

língua portuguesa encerra a ideia de diferente ou anômalo, trazendo-o para o contexto jurídico, trata-se de um terceiro que desempenha um papel diferente dos demais, colocando-se em outra posição. ${ }^{33}$

Por outro lado, introduz-se a autocomposição, tradicionalmente percebida como a resolução de uma controvérsia através do sacrifício voluntário ${ }^{34}$ de seus interesses, total ou parcialmente, por uma das pessoas, em favor do interesse do outro. Autocomposição (auto + composição) também é um substantivo feminino que, juridicamente, representa uma "forma de resolução de conflitos através de acordo sem intervenção da Justiça" 35 . Ainda, a palvra é apresentada como sinônimo de acordo ou concordância entre as partes, sendo, juridicamente, classificada enquanto "maneira de resolver litígios, estabelecendo um acordo, sem que haja a interferência de órgãos judiciais". ${ }^{36}$ Bem como, conforme o dicionário Michaelis: "JUR Processo de conciliação e resolução de interesses conflitantes por meio de acordos ou compromisso das partes, sem a intervenção de autoridade judiciária. Etimologia: autós+composição". 37

Na prática, a autocomposição implicaria de um ato de disposição total ou parcial do bem jurídico em discussão, abre-se mão de parte daquilo que se achava ter direito. Entretanto, esse sentido da autocomposição já não é o único, nem o mais relevante, isso se deve a pelo menos três fatores: a) as transformações sofridas pelo direito material, que em muitos casos não comporta uma divisão absoluta entre o que é privado e disponível e público e indisponível; b) a crescente valorização de meios paralelos à adjudicação para a resolução de conflitos, com ênfase na possibilidade/necessidade de cada sujeito (seja na esfera pública ou privada); c) a ratificação de princípios como legalidade, razoabilidade e moralidade (boa-fé) como parâmetro de atuação dos entes públicos (e de seus entes descentralizados ou delegatários), o que importa também em uma atuação proativa desses

\footnotetext{
${ }^{32}$ Regulamentada pela Lei n. 9.307/1996 (BRASIL. Lei no 9.307 (1996). Brasília: Senado Federal, 23 set. 1996).

33 HETERO. In: Dicionário Priberam da Língua Portuguesa, 2008-2013. Disponível em: https://www.priberam.pt/dlpo/hetero-. Acesso em: 18 set. 2017.

${ }^{34}$ Diferente da autotutela, o sacrifício voluntário não é condizente com a ideia de violência.

35 AUTOCOMPOSIÇÃO. In: Dicionário Priberam da Língua Portuguesa, 2008-2013. Disponível em: https://www.priberam.pt/dlpo/autocomposi\%C3\%A7\%C3\%A3o. Acesso em: 18 set. 2017.

36 AUTOCOMPOSIÇÃO. In: Dicionário online de Português, 2009-2017. Disponível em: https://www.dicio.com.br/autocomposicao/. Acesso em: 18 set. 2017.

37 AUTOCOMPOSIÇÃO. In: Dicionário Brasileiro da Língua Portuguesa Michaelis. São Paulo: Melhoramentos, 2017. Disponível em: http://michaelis.uol.com.br/moderno-portugues/busca/portuguesbrasileiro/autocomposi\%C3\%A7\%C3\%A3o/. Acesso em: 18 set. 2017.
} 
Revista Eletrônica de Direito Processual - REDP.

Rio de Janeiro. Ano 11. Volume 18. Número 3. Setembro a Dezembro de 2017

Periódico Quadrimestral da Pós-Graduação Stricto Sensu em Direito Processual da UERJ

Patrono: José Carlos Barbosa Moreira. ISSN 1982-7636. pp. 69-93

www.redp.uerj.br

entes, antecipando a improcedência da sua posição em um potencial conflito para que, desde logo, tome as medidas possíveis para resolver a situação. ${ }^{38}$

Dessa forma, tem-se uma segunda acepção de autocomposição. Não se referindo apenas a uma renúncia de direito material que se julga possuir, mas sim a verificação pelo próprio conflitante de que não possui razão, no todo ou em parte, com consequente adoção de providências em prol do consenso para com o outro. Muitas vezes é dispensável questionar o motivo pelo qual as partes estão compondo, se é pela simples renúncia ou se constatam a improcedência da sua pretensão/posição. Todavia, a distinção é importante para casos em que o bem jurídico em disputa não é renunciável (há um direito material indisponível), hipótese em que não seria adequada a autocomposição no primeiro sentido, mas viável no segundo formato. ${ }^{39}$

Vale-se dessa segunda acepção para lidar com os conflitos envolvendo entes da Administração Pública, uma vez que existe a necessidade de respeitar alguns princípios como o da legalidade ${ }^{40}$, impessoalidade ${ }^{41}$, moralidade ${ }^{42}$, publicidade $^{43}$, eficiência ${ }^{44}$, além da indisponibilidade do interesse público e da supremacia do interesse público sobre o

\footnotetext{
${ }^{38}$ WAMBIER, Luiz Rodrigues; TALAMINI, Eduardo. Curso avançado de processo civil: teoria geral do processo. São Paulo: Editora Revista dos Tribunais, 2016a. ${ }^{39}$ Idem.

40 A legalidade é considerada uma das garantias de respeito aos direitos individuais, pois a lei que os estabelece também prevê um limite da atuação da administração em prol dos benefícios coletivos. A vontade da administração pública estaria adstrita a lei e dela seria decorrente, podendo fazer aquilo que a lei permite. Enquanto no âmbito privado, as pessoas podem fazer aquilo que a lei não proíbe. Nesse sentido é o posicionamento de: DI PIETRO, Maria Sylvia Zanella. Direito administrativo. Rio de Janeiro: Forense, 2016.

41 A impessoalidade busca o tratamento em patamar de igualdade aos administrados, a fim de se evitar favorecimentos. Ainda, deve a administração motivar a sua conduta, justificando a razão do acordo. Nesse sentido é o posicionamento de: SPENGLER. Fabiana Marion. Mediação de conflitos: da teoria à prática. Porto Alegre: Livraria do Advogado, 2017.

${ }^{42}$ A moralidade administrativa por muitos autores não é considerada um princípio, é uma disciplina que se desenvolveu com o passar do tempo e que na atualidade pode ser resumida como um comportamento, que inserido na matéria administrativa, ainda que de acordo com a lei, ofenda a moral, os bons costumes, a boa administração, a justiça e a equidade.

43 A publicidade é a ampla divulgação daquilo que é praticado pela administração, desde que não seja hipótese de sigilo prevista na lei.

${ }_{44}$ A eficiência seria o modo de atuação do agente público - do qual é esperado o melhor desempenho possível - e o modo de organização e estruturação da administração, visando os melhores resultados. Sobre o tema, recomenda-se a leitura de artigo sobre a transparência na Administração Pública e os impactos positivos que isso pode gerar: BLANCHET, Luiz Alberto. A transparência na administração pública, o combate à corrupção e os impactos no desenvolvimento. Revista do Direito, vol. 01, $\mathrm{n}^{\circ}$ 51. Santa Cruz do Sul, 2017.
} 
Revista Eletrônica de Direito Processual - REDP.

Rio de Janeiro. Ano 11. Volume 18. Número 3. Setembro a Dezembro de 2017

Periódico Quadrimestral da Pós-Graduação Stricto Sensu em Direito Processual da UERJ

Patrono: José Carlos Barbosa Moreira. ISSN 1982-7636. pp. 69-93

www.redp.uerj.br

privado $^{45}$. No momento em que se percebe um conflito, no qual a conduta administrativa

está equivocada, o ente pode tratá-lo preventivamente, envidando esforços no sentido de resolvê-lo através de alguma modalidade de acordo como o de adesão, por exemplo.

Assim, restariam, respeitados os princípios administrativos, e, ao mesmo tempo, evitar-seia uma série de ações judiciais repetitivas. Entretanto, cumpre questionar se esse formato de acordo, ou qualquer outra negociação pactuada com o Estado (ainda que não seja em massa) poderia ser tratada enquanto autocomposição. Por isso, busca-se compreender, através de classificações doutrinárias, qual a terminologia e forma adequadas para se dirigir a esse tipo de conflito - entre Estado e particular.

De acordo com Luiz Rodrigues Wambier e Eduardo Talamini, ${ }^{46}$ a automposição é gênero, do qual são espécies a transação em sentido estrito (concessões e/ou reconhecimentos mútuos), a total submissão à pretensão alheia, e a total renúncia da própria pretensão. Em sentido amplo, o autor se refere a essas três espécies como transação. Ainda, a autocomposição não se reserva apenas a uma etapa pré-processual, ela pode ocorrer dentro do processo ou paralelamente a este também, bem como, o acordo dela decorrente pode ser levado para homologação judicial, caso em que o seu posterior descumprimento implicaria na possibilidade de execução nos termos do artigo 515, II, III do $\mathrm{CPC}^{47}$.

Atualmente, com a intenção de estimular a autocomposição, o CPC prevê a possibilidade de cada tribunal criar um setor de conciliação e/ou mediação ou de

\footnotetext{
${ }^{45}$ Quando da elaboração da lei, bem como no momento da sua execução, a atuação do administrador deve ser pautada no princípio da supremacia do interesse público. Tal princípio inspira o legislador e vincula a autoridade administrativa na sua atuação, provoca o ente público a considerar o interesse que se pretende proteger - normas de interesse coletivo. Contudo, ele não é absoluto, deve-se analisar a norma que irá beneficiar a coletividade, proporcionando o bem-estar social, ocorre que, por vezes, pode uma norma de direito privado beneficiar a sociedade de forma mais ampla que uma norma de interesse coletivo. Ademais, tais normas nem sempre possuem uma segmentação clara, por exemplo, o direito de família é Direito privado que por consequência atinge a esfera pública, assim como a segurança é um interesse coletivo que atinge o particular e sua vida privada. Assim, verifica-se uma linha tênue entre o interesse coletivo e individual, devendo-se considerar as situações isoladas e tentar dimensionar o seu impacto coletivo e social. Nesse sentido é o posicionamento de: DI PIETRO, Maria Sylvia Zanella. Direito administrativo. Rio de Janeiro: Forense, 2016.

${ }^{46}$ WAMBIER, Luiz Rodrigues; TALAMINI, Eduardo. Curso avançado de processo civil: teoria geral do processo. São Paulo: Editora Revista dos Tribunais, 2016a.

${ }^{47}$ Art. 515. São títulos executivos judiciais, cujo cumprimento dar-se-á de acordo com os artigos previstos neste Título: I - as decisões proferidas no processo civil que reconheçam a exigibilidade de obrigação de pagar quantia, de fazer, de não fazer ou de entregar coisa; II - a decisão homologatória de autocomposição judicial; III - a decisão homologatória de autocomposição extrajudicial de qualquer natureza; [...] (BRASIL. Código de Processo Civil (2015). Brasília: Senado Federal, 2015).
} 
Revista Eletrônica de Direito Processual - REDP.

Rio de Janeiro. Ano 11. Volume 18. Número 3. Setembro a Dezembro de 2017

Periódico Quadrimestral da Pós-Graduação Stricto Sensu em Direito Processual da UERJ Patrono: José Carlos Barbosa Moreira. ISSN 1982-7636. pp. 69-93

www.redp.uerj.br

programas com o mesmo objetivo (artigos 165 e seguintes do $\mathrm{CPC})^{48}$. A mediação e a conciliação, conforme classificação de Luiz Rodrigues Wambier e Eduardo Talamini, ${ }^{49}$ são espécies de autocomposição coordenadas por uma terceira pessoa, o mediador ou o conciliador, que atua no sentido de facilitar a comunicação entre os conflitantes. A distinção entre esses dois mecanismos, por vezes, enfrenta algumas divergências de ordem doutrinária, todavia, atualmente, o $\mathrm{CPC}$ veicula conceitos legais das duas modalidades de tratamento de conflitos.

O mediador atua preferencialmente em casos nos quais as partes compartilham um vínculo anterior ao conflito, buscando auxiliar as pessoas no reestabelecimento da comunicação, a fim de que estas identifiquem por si próprias uma resposta satisfatória ao problema, conforme art. $165, \S 3^{\circ}$ do $\mathrm{CPC}^{50}$. Enquanto o $\S 2^{\circ}$ estabelece que o conciliador atuará, preferencialmente, em casos sem vinculação anterior entre os envolvidos, cabendolhe apresentar sugestões e possibilidades com a finalidade de resolver a questão, contudo, não pode o conciliador coagir, intimidar ou impor alguma solução. Em suma, o mediador assume uma postura de facilitador, deixando com que as próprias pessoas construam e trabalhem numa resposta que lhes seja adequada, já o conciliador possui uma postura um pouco mais ativa, podendo sugerir opções/alternativas para a solução do dilema.

De outra parte, na teoria de Leonard Riskin, esse terceiro facilitador/avaliador poderia ser classificado de quatro formas: a) o facilitador restrito: é aquele que pode perguntar, ajudar as pessoas a desenvolverem suas próprias propostas restritivas, a trocarem propostas e avaliar as propostas trocadas; b) facilitador amplo: o terceiro ajuda os conflitantes a compreenderem seus interesses subjacentes, auxiliando-os a desenvolverem alternativas pautadas nos seus próprios interesses; c) avaliador restrito: o terceiro tem a prerrogativa de estimular pontos fortes e fracos de cada envolvido, prever resultados de

\footnotetext{
48 Sobre a cooperação, considerando o novo contexto processual civil e a ampliação de mecanismos consensuais, recomenta-se a leitura do artigo: PINHO, Humberto Dalla Bernardina de; ALVES; Tatiana Machado. A cooperação no novo código de processo civil: desafios concretos para sua implementação. Revista Eletrônica de Direito Processual. Rio de Janeiro, vol. 15, n. 15, 2015.

${ }^{49}$ WAMBIER, Luiz Rodrigues; TALAMINI, Eduardo. Op. cit.

${ }^{50}$ Art. 165. Os tribunais criarão centros judiciários de solução consensual de conflitos, responsáveis pela realização de sessões e audiências de conciliação e mediação e pelo desenvolvimento de programas destinados a auxiliar, orientar e estimular a autocomposição. [...] $\S^{3} \mathrm{O}$ mediador, que atuará preferencialmente nos casos em que houver vínculo anterior entre as partes, auxiliará aos interessados a compreender as questões e os interesses em conflito, de modo que eles possam, pelo restabelecimento da comunicação, identificar, por si próprios, soluções consensuais que gerem benefícios mútuos (BRASIL. Código de Processo Civil (2015). Brasília: Senado Federal, 2015).
} 
Revista Eletrônica de Direito Processual - REDP.

Rio de Janeiro. Ano 11. Volume 18. Número 3. Setembro a Dezembro de 2017

Periódico Quadrimestral da Pós-Graduação Stricto Sensu em Direito Processual da UERJ

Patrono: José Carlos Barbosa Moreira. ISSN 1982-7636. pp. 69-93

www.redp.uerj.br

processos judiciais e propor contratos de compromisso, incentivando o acordo; d) avaliador

amplo: promover a conscientização e respeito dos direitos subjacentes, prevendo impactos da não composição, auxiliando no desenvolvimento de propostas e aceitação mútua. ${ }^{51}$

Esse modelo graduado proposto por Leonard Riskin ${ }^{52}$ pode não parecer adequado, na medida em que o mediador parece impor uma solução às partes, ao tempo em que estas estariam participando de uma autocomposição. Esse autor subdivide essas características restritivas e amplas do terceiro enquanto diferentes espécies de um modelo de mediação. Apesar de tal concepção não se enquadrar aos moldes brasileiros, conforme os artigos referenciados do CPC, ela se torna relevante na medida em que traz mais uma forma de perceber os gêneros e espécies classificatórios das possíveis dimensões de se lidar com conflitos.

Retomando a ideia de Niceto Alcalá Zamora y Castillo, ${ }^{53}$, desenvolveu-se um quadro resumo com a finalidade de demonstrar quem é o responsável pela resolução e qual a metodologia utilizada na autotutela, na autocomposição e na heterocomposição: Figura 1.

Nota-se que a autotutela é caracterizada pela vitória do mais forte, pela aniquilação do outro. ${ }^{54}$ Porém, o que é mais relevante ao desenvolvimento deste artigo é a concepção de autocomposição e de heterocomposição. Enquanto na primeira hipótese se trabalha na perspectiva de responsabilidade própria, de autonomia, de uma conversa direta entre as pessoas no formato de uma negociação (assistida ou não), ou seja, podendo ser facilitada por um terceiro sem poder decisório, no segundo caso, percebe-se a presença de um terceiro com poder decisório, que ditará os direitos, elegendo um vencedor e um perdedor. $^{55}$

\footnotetext{
${ }^{51}$ RISKIN, Leonard. Compreendendo as orientações, estratégias e técnicas do mediador: um padrão para perplexos. In: AZEVEDO, André Gomma de (org.). Estudos em arbitragem, mediação e negociação. Brasília: Brasília Jurídica, 2002. Disponível em: http://www.ipea.gov.br/ouvidoria/images/stories/pdf/ mediacao_negociacao_volume1.pdf. Acesso em: 15 set. 2017.

${ }^{52}$ Idem.

${ }^{53}$ CASTILLO, Niceto Alcalá Zamora y. Proceso, autocomposición y autodefensa. México: Universidad Nacional Autónoma de México, 1991.

${ }_{55}^{54}$ Reflete-se acerca da ideia de conflito trabalhada no primeiro tópico.

${ }^{55}$ A autocomposição opera sob a lógica do ganha-ganha enquanto a heterocomposição comporta um vencedor, lógica do perde-ganha. Nesse sentido é a leitura de: SALES, Lilia Maia de Moraes. Mediare: um guia prático para mediadores. Rio de Janeiro: GZ ed., 2010.
} 
Revista Eletrônica de Direito Processual - REDP.

Rio de Janeiro. Ano 11. Volume 18. Número 3. Setembro a Dezembro de 2017

Periódico Quadrimestral da Pós-Graduação Stricto Sensu em Direito Processual da UERJ

Patrono: José Carlos Barbosa Moreira. ISSN 1982-7636. pp. 69-93

www.redp.uerj.br

Ainda, sob um outro prisma, destaca-se a concepção de Fabiana Marion Spengler, ${ }^{56}$

ponderando a posição política e sociológica do terceiro (incluído e excluído) na gestão dos conflitos. Enquanto o terceiro (mediador) está incluído na dinâmica conflitiva, formando um sistema a três. O árbitro e o juiz formam um sistema com terceiro, pois ditam o direito das pessoas envolvidas em determinada controvérsia. Assim, analisam-se a autocomposição e a heterocomposição a partir da posição do terceiro - se incluído ou excluído, entendendo-se por estar esse incluído na autocomposição e formando um sistema com terceiro (excluído) na heterocomposição. Essa organização é diferenciada e, em muito contribui, para as análises aqui propostas.

Assim, uma vez compreendidos os significados da hetero e da autocomposição, parte-se para a apreciação das diferentes posições doutrinárias quanto à classificação dessas dimensões de lidar com os conflitos. Em regra, salvo a posição de Riskin ao classificar a mediação enquanto gênero de possíveis espécies restritas ou amplas de mediador, os demais autores mencionados consideram a hetero e a autocomposição enquanto gênero, dos quais decorrem os mecanismos específicos de transação no caso da autocomposição $^{57}$ e da arbitragem, decisão administrativa e adjudicação na heterocomposição.

A ideia não é refutar as diferentes posições doutrinárias quanto à classificação das dimensões dos diferentes mecanismos de lidar com os conflitos, mas sim, propor mais um olhar sobre essa categorização, a partir dos pressupostos da Lei n. 13.140/2015 elencados no Capítulo II da Lei, que trata da autocomposição de conflitos em que for parte Pessoa Jurídica de Direito Público.

\footnotetext{
56 “O juiz e o árbitro são Terceiros - o primeiro determinado pelo Judiciário e o segundo eleito pelos conflitantes - para solucionar as divergências. Ao contrário do mediador, o juiz e o árbitro possuem poder de decisão. O cumprimento dessa decisão é obrigatório, podendo ser alvo de execução. O árbitro, especificamente, deve ser um técnico ou um especialista no assunto em discussão para dar um parecer e decidir a controvérsia. A ele se atribui o poder do juiz, e sua decisão é soberana [...] O papel do Terceiro imparcial, aquele caracterizado como "parte não interessada", definido anteriormente como alguém que não está implicado pessoalmente no conflito, é possível encontrar a figura de um moderador que se esforça em solucionar o problema. Esse espaço pode ser atribuído ao mediador22, considerando que os resultados positivos ocorrerão desde que ele seja reconhecido como tal por ambos os conflitantes [...] Para cumprir com esse fim importa dizer que, na mediação, é possível reconhecer um "sistema a três". Nesse sistema, a figura do Terceiro (mediador) é aquela que usa a mesma linguagem dos conflitantes, tornando-se o coágulo entre um e outro. Por outro lado, a jurisdição é um "sistema com Terceiro", porém um Terceiro que não se mistura com os conflitantes. É onde encontramos a metalinguagem, a linguagem da lei” (SPENGLER, Fabiana Marion. Uma relação à três: o papel político e sociológico do terceiro no tratamento dos conflitos. Revista Dados, vol. 59, $\mathrm{n}^{\circ}$ 2. Rio de Janeiro abr./jun., 2016).

${ }^{57}$ Como exemplo, citam-se a negociação, a conciliação e a mediação.
} 


\section{A (AUTO)COMPOSIÇÃO EM CONFLITOS COM A ADMINISTRAÇÃO PÚBLICA}

Não faz muito tempo, a mediação e a conciliação eram consideradas formas "alternativas" de tratamento de conflitos, sendo tratadas como opções secundárias em relação ao modelo judiciário de imposição heterônoma, também conhecido como modelo adjudicatório. Essa alternatividade passa a ser encarada não como uma opção ou recurso secundário, mas como mecanismo de ordem paralela na resolução de conflitos. Isso significa que o conflito pode ser direcionado ao método que lhe for mais adequado ${ }^{58}$, podendo este ser a conciliação, a mediação, a arbitragem, a adjudicação, etc.

$\mathrm{O}$ artigo 139, V do CPC inclui dentre os deveres do magistrado promover em qualquer momento do rito processual, a autocomposição, preferencialmente com assistência/apoio dos conciliadores e mediadores judiciais. A autocomposição (gênero), compreendida/subdividida no artigo $139, \mathrm{~V}$ em conciliação e mediação (espécies) ${ }^{59}$ são diferenciadas nos termos dos parágrafos $2^{\circ}$ e $3^{\circ}$ do artigo 165 do CPC. A conciliação prioriza casos em que não haja vínculo anterior entre as partes, sendo que o conciliador poderá sugerir soluções ao conflito, vedando-se quaisquer práticas constrangedoras ou intimidadoras. Já a mediação é recomendada aos casos em que houver um vínculo anterior entre as partes, sendo papel do mediador auxiliar aos interessados compreender as questões e interesses em conflito a fim de reestabelecer a comunicação, devendo as próprias pessoas identificar possibilidades à resolução dos seus problemas.

De acordo com determinação do artigo 334 do CPC, caso a petição inicial preencha aos requisitos essenciais do artigo 319 do CPC e não se configure a improcedência liminar do pedido ${ }^{60}$, o juiz designará audiência de conciliação ou de mediação, respeitando a

\footnotetext{
58 Trabalha-se na perspectiva adotada pelo Fórum Múltiplas Portas, modelo que prevê uma central de encaminhamento (distribuição) dos casos à porta (método) que pareça a mais adequada para seu tratamento.

${ }^{59}$ Classificação extraída da obra de WAMBIER, Luiz Rodrigues; TALAMINI, Eduardo. Curso avançado de processo civil: cognição jurisdicional (processo comum de conhecimento e tutela provisória). São Paulo: Editora Revista dos Tribunais, 2016 b.

${ }^{60}$ Art. 332. Nas causas que dispensem a fase instrutória, o juiz, independentemente da citação do réu, julgará liminarmente improcedente o pedido que contrariar: I - enunciado de súmula do Supremo Tribunal Federal ou do Superior Tribunal de Justiça; II - acórdão proferido pelo Supremo Tribunal Federal ou pelo Superior Tribunal de Justiça em julgamento de recursos repetitivos; III - entendimento firmado em incidente de resolução de demandas repetitivas ou de assunção de competência; IV - enunciado de súmula de tribunal de
} 
Revista Eletrônica de Direito Processual - REDP.

Rio de Janeiro. Ano 11. Volume 18. Número 3. Setembro a Dezembro de 2017

Periódico Quadrimestral da Pós-Graduação Stricto Sensu em Direito Processual da UERJ Patrono: José Carlos Barbosa Moreira. ISSN 1982-7636. pp. 69-93

www.redp.uerj.br

antecedência mínima de 30 (trinta) dias e a citação do réu com pelo menos 20 (vinte) dias de antecedência. Além disso, é pressuposto da realização da audiência de conciliação e mediação, que ambas as partes não tenham manifestado seu desinteresse no procedimento de mediação ou concliação, conforme disposição do artigo $334, \S 4^{\circ}$, I do CPC. ${ }^{61}$

Em 1994, através da Lei n. 8.952, quando a audiência de conciliação foi introduzida no processo civil, posteriormente transformada, por nova reforma do CPC/1973, em audiência preliminar, o legislador cometeu um equívoco ao torná-la cabível apenas aos conflitos que envolvessem "direitos disponíveis". Afinal, há pretensões que, apesar de indisponíveis, comportam a autocomposição, como disputas relacionadas à guarda de menores, conflitos envolvendo direitos difusos, a transação com a administração pública ${ }^{62}$. Nesse sentido, o CPC inovou ao prever o cabimento da audiência de conciliação e mediação sempre que a causa comportar a autocomposição. ${ }^{63}$

Percebe-se que a tradicional visão de meios alternativos, como uma justiça secundária, restrita ao tratamento de conflitos que versem apenas sobre direitos disponíveis está sofrendo mudanças, há uma ampliação na tipologia de conflitos, alvo de outros mecanismos, que não a adjudicação. Sobre o assunto é a Lei n. 13.140/2015 que dispõe sobre a mediação entre particulares como meio de solução de controvérsias e sobre a autocomposição de conflitos, no âmbito da administração pública.

O capítulo II da Lei ${ }^{64}$ é intitulado: "DA AUTOCOMPOSIÇÃO DE CONFLITOS EM QUE FOR PARTE PESSOA JURÍDICA DE DIREITO PÚBLICO”, observa-se que o título utiliza da terminologia autocomposição, ao passo que o art. 32 estabelece a possibilidade da criação de Câmaras de Prevenção e Resolução Administrativa de

justiça sobre direito local. $\S 1^{\circ} \mathrm{O}$ juiz também poderá julgar liminarmente improcedente o pedido se verificar, desde logo, a ocorrência de decadência ou de prescrição. $§ 2^{\underline{0}}$ Não interposta a apelação, o réu será intimado do trânsito em julgado da sentença, nos termos do art. 241. $\S 3^{\circ}$ Interposta a apelação, o juiz poderá retratarse em 5 (cinco) dias. $\S 4^{\underline{0}}$ Se houver retratação, o juiz determinará o prosseguimento do processo, com a citação do réu, e, se não houver retratação, determinará a citação do réu para apresentar contrarrazões, no prazo de 15 (quinze) dias (BRASIL. Código de Processo Civil (2015). Brasília: Senado Federal, 2015).

${ }^{61}$ Não basta que apenas uma das partes de manifeste quanto ao desinteresse no procedimento, nos termos do artigo, ambas precisam se manifestar nesse sentido.

62 Em regra os bens e os interesses da administração pública são indisponíveis, pois pertencentes à coletividade. Contudo, essa prerrogativa, por vezes, pode ser flexibilizada.

63 Art. 334. Se a petição inicial preencher os requisitos essenciais e não for o caso de improcedência liminar do pedido, o juiz designará audiência de conciliação ou de mediação com antecedência mínima de 30 (trinta) dias, devendo ser citado o réu com pelo menos 20 (vinte) dias de antecedência. [...] § 4º A audiência não será realizada: [...] II - quando não se admitir a autocomposição (BRASIL. Código de Processo Civil (2015). Brasília: Senado Federal, 2015).

${ }^{64}$ BRASIL. Lei no 13.140 (2015). Brasília: Senado Federal, 26 jun. 2015. 
Revista Eletrônica de Direito Processual - REDP.

Rio de Janeiro. Ano 11. Volume 18. Número 3. Setembro a Dezembro de 2017

Periódico Quadrimestral da Pós-Graduação Stricto Sensu em Direito Processual da UERJ Patrono: José Carlos Barbosa Moreira. ISSN 1982-7636. pp. 69-93

www.redp.uerj.br

Conflitos, sendo incumbência das referidas Câmaras "avaliar a admissibilidade dos pedidos de resolução de conflitos, por meio de composição, no caso de controvérsia entre particular e pessoa jurídica de direito público". ${ }^{65}$ Observa-se a utilização da expressão “composição" no art. 32, II da Lei n. 13.140/2015, de modo que se passa a averiguar o que isso representa enquanto dimensão de resolução de conflitos.

Composição, substantivo feminino, do latim compositio $=$ acordo, "Dir. Obr. Entendimento entre as partes, mediante concessões mútuas, para dirimir uma pendência. $\mathrm{O}$ mesmo que transação". ${ }^{66}$ Também quer dizer: "acordo feito entre os litigantes a fim de dar uma solução à demanda". ${ }^{67}$ Ou ainda, conforme o dicionário Aurélio online, é o

todo (proveniente da reunião de partes); Modo de reunir partes (para formar um todo); Produção; Preparado; Disposição; Combinação; Matéria; Acordo (entre desavindos); Arte de escrever música; Trecho ou peça musical; Processo de formação de palavras em que ocorre a junção de elementos autônomos, normalmente palavras, mas também radicais gregos e latinos; Resultado das forças e movimentos; Agrupamento de moléculas; Modo por que elas se agrupam; Trabalho de compositor; Original composto. ${ }^{68}$

Outros dicionários, como o Priberam ${ }^{69}$ e Michaelis $^{70}$ trazem significados semelhantes ao do Aurélio. Composição é o ato ou efeito de compor. ${ }^{71}$ A autocomposição

65 Esse artigo reproduz o art. 174 do CPC: “Art. 174. A União, os Estados, o Distrito Federal e os Municípios criarão câmaras de mediação e conciliação, com atribuições relacionadas à solução consensual de conflitos no âmbito administrativo, tais como: I - dirimir conflitos envolvendo órgãos e entidades da administração pública; II - avaliar a admissibilidade dos pedidos de resolução de conflitos, por meio de conciliação, no âmbito da administração pública; III - promover, quando couber, a celebração de termo de ajustamento de conduta" (BRASIL. Código de Processo Civil (2015). Brasília: Senado Federal, 2015).

${ }^{66}$ SIDOU, J.M. Othon (org.). Dicionário jurídico. Rio de Janeiro: Forense Universitária, 1991, p. 121.

${ }^{67}$ MELLO, Maria Chaves de. Dicionário jurídico português-inglês. São Paulo: Método, 2006, p. 133.

68 COMPOSIÇÃO. In: Dicionário Aurélio Online da Língua Portuguesa, 2016. Disponível em: https://dicionariodoaurelio.com/composicao. Acesso em: 18 set. 2017.

69 "Com·po·si·ção (latim compositio, -onis), substantivo feminino: 1. Todo (proveniente da reunião de partes). 2. Modo de reunir partes (para formar um todo). 3. Produção. 4. Preparado. 5. Disposição. 6. Combinação. 7. Matéria. 8. Acordo (entre desavindos). 9. Arte de escrever música. 10. Trecho ou peça musical. 11. [Linguística] Processo de formação de palavras em que ocorre a junção de elementos autônomos, normalmente palavras, mas também radicais gregos e latinos. 12. [Mecânica] Resultado das forças e movimentos. 13. [Física] Agrupamento de moléculas. 14. Modo por que elas se agrupam. 15. [Artes gráficas] Montagem ou arranjo de material tipográfico para impressão. 16. [Tipografia] Trabalho feito pelo tipógrafo. 17. [Tipografia] Original composto" (COMPOSIÇÃO. In: Dicionário Priberam da Língua Portuguesa, 2008-2013. Disponível em: https://www.priberam.pt/dlpo/composi\%C3\%A7\%C3\%A3o. Acesso em: 18 set. 2017). 
Revista Eletrônica de Direito Processual - REDP.

Rio de Janeiro. Ano 11. Volume 18. Número 3. Setembro a Dezembro de 2017

Periódico Quadrimestral da Pós-Graduação Stricto Sensu em Direito Processual da UERJ

Patrono: José Carlos Barbosa Moreira. ISSN 1982-7636. pp. 69-93

www.redp.uerj.br

e a heterocomposição derivam da palavra composição. Morfologicamente, trata-se de uma prefixação que altera, em parte, o significado da palavra. Elas não são antagônicas, nem complementares, sendo distintivas entre si. O processo de prefixação tem o condão de operar nesse sentido, podendo ressignificar a palavra.

Sob o ponto de vista jurídico, o acordo autocompositivo se realiza sem a intervenção judicial ou de um terceiro com poder decisório, já na composição, o acordo pode ser realizado também na presença do Poder Judiciário. Esse é o ponto que distingue a autocomposição da composição, pois ambas representam mecanismos consensuais, diferenciando-se em razão da prefixação: (auto)composição - acordo conduzido pelas próprias partes ou por terceiro sem poder decisório.

Partindo-se desse debate, entende-se que, quando o conflito for tratado pela Câmara de Prevenção e Resolução de Conflitos, por um facilitador sem poder decisório, poderá ser alvo de autocomposição. Diferentemente de uma decisão administrativa em que a Administração Pública atua como julgadora do conflito - caso em que se fala de heterocomposição.

Para Batista Junior ${ }^{72}$, a transação no Direito Administrativo requer cinco elementos básicos: a) uma controvérsia/conflito no qual a Administração Pública seja parte; b) vontade de transigir/negociar; c) capacidade do interessado e competência administrativa para fazer o acordo/transigir; d) objeto do conflito transacionável; e) concessões recíprocas. Com o advento da Lei n. 13.140/2015, autoriza-se aos entes federados a criação de leis conferindo competência para a transação e a prevenção de conflitos no âmbito

\footnotetext{
70 “Composição, com·po·si.ção sf: 1 Ação de compor(-se). 2 Ação de constituir um todo. 3 Forma pela qual os componentes se organizam em um todo. 4 QUÍM Proporção em que os elementos se unem para formar um todo. 5 QUÍM Modo pelo qual as moléculas de um corpo se organizam. 6 FARM Associação de substâncias medicamentosas. 7 Conjunto de vagões de trem, nas estradas de ferro. 8 GRAM Reunião de uma ou mais palavras em orações. 9 GRAM Reunião de orações em períodos ou discursos. 10 GRAM Formação de uma nova palavra pela combinação de dois elementos vocabulares de significação própria. 11 MÚS Obra musical elaborada de acordo com as regras da arte. 12 Produção literária, científica ou artística. 13 GRÁF O trabalho de compositor tipográfico. 14 GRÁF As linhas e páginas de caracteres, fios e vinhetas, juntados e combinados pelo tipógrafo, para a impressão de qualquer trabalho. 15 METAL Liga de metais que dá aparência similar à prata. 16 POLÍT Convenção política em que os partidos assumem compromisso de união ou de convivência" (COMPOSIÇÃO. In: Dicionário Brasileiro da Língua Portuguesa Michaelis. São Paulo: Melhoramentos, 2017. Disponível em: http://michaelis.uol.com.br/modernoportugues/busca/portugues-brasileiro/composi\%C3\%A7\%C3\%A3o/. Acesso em: 18 set. 2017).

${ }^{71}$ FERRERIA, Aurélio Buarque de Holanda. Novo Aurélio Século XXI: o dicionário da língua portuguesa. Rio de Janeiro: Nova Fronteira, 1999, p. 514.

${ }^{72}$ BATISTA JUNIOR, Onofre Alves. Transações administrativas. São Paulo: Quartier Latin, 2007.
} 
Revista Eletrônica de Direito Processual - REDP.

Rio de Janeiro. Ano 11. Volume 18. Número 3. Setembro a Dezembro de 2017

Periódico Quadrimestral da Pós-Graduação Stricto Sensu em Direito Processual da UERJ

Patrono: José Carlos Barbosa Moreira. ISSN 1982-7636. pp. 69-93

www.redp.uerj.br

administrativo. Trata-se de um marco legislativo importante, que viabiliza uma forma

diferenciada de organização ao atendimento dos conflitos no seio da sociedade.

\section{CONCLUSÃO}

Os conflitos são inevitáveis, eles estruturam as relações sociais e atuam enquanto propulsores de mudanças. A sua gestão adequada confere benefícios à sociedade, enquanto a má administração dos problemas pode acarretar prejuízos. O Estado é um dos maiores litigantes da Justiça, tal situação incita uma reflexão acerca do tema, provocando mudanças legislativas como a reestruturação do CPC e o advento da Lei n. 13.140/2015.

Ao abordar as diferentes dimensões de lidar com os conflitos, pretendeu-se diferenciar a hetero e a autocomposição, uma vez que são essencialmente formas de resolução de controvérsias, porém, com abordagens distintas. Elas derivam de uma mesma palavra original, mas distanciam-se desta ao analisar os seus significados. Nesse passo, percebe-se que ambas são gêneros representativos de espécies de modalidades ou mecanismos auto ${ }^{73}$ ou hetercompositivos, ${ }^{74}$ também tratados pela doutrina como espécies.

Os conflitos envolvendo a administração pública requerem um tratamento diferenciado, pois precisam respeitar aos princípios administrativos, pressupõe uma lei que autorize a transação e competência do ente, além de orientar limites às possíveis concessões. Quanto às expressões utilizadas pela Lei n. 13.140/2015, entende-se que a autocomposição é possível, uma vez que a própria administração pública integra um dos polos da controvérsia. Por outro lado, a composição pressupõe uma abordagem mais ampla, não se limitando ao acordo transacionável apenas pelas próprias partes ou por terceiro sem poder decisório. Ainda, é possível compor na presença de terceiro com poder decisório.

Conforme elucidado, morfologicamente, hetero e autocomposição derivam de uma origem comum - a composição, sendo a heterocomposição, juridicamente, composta por um terceiro imparcial com poder decisório. Enquanto na segunda hipótese (autocomposição), o terceiro atua como facilitador ou as próprias partes negociam diretamente sem um terceiro. Nesse sentido, quanto à formação da palavra, temos uma

\footnotetext{
${ }^{73}$ Negociação, conciliação e mediação.

${ }^{74}$ Arbitragem, decisão administrativa e adjudicação.
} 
Revista Eletrônica de Direito Processual - REDP.

Rio de Janeiro. Ano 11. Volume 18. Número 3. Setembro a Dezembro de 2017

Periódico Quadrimestral da Pós-Graduação Stricto Sensu em Direito Processual da UERJ

Patrono: José Carlos Barbosa Moreira. ISSN 1982-7636. pp. 69-93

www.redp.uerj.br

origem comum, mas, transportando essa para o sentido jurídico é possível perceber que a heterocomposição se afasta do princípio transacional, trabalhando na ótica de uma decisão imposta. $^{75}$

Assim, se o mecanismo selecionado para tratar do conflito entre a administração pública e o particular permitir a gestão dos conflitos através da vontade dos envolvidos, fala-se em autocomposição. Todavia, havendo a presença de um terceiro que venha ter poder decisório, como em um acordo realizado em juízo, recomenda-se a utilização da terminologia composição, uma vez que o prefixo "auto" se traduz na autonomia e liberdade dos conflitantes em um ambiente não judicial.

Do ponto de vista do papel desempenhado pelo terceiro, pode-se considerar que na autocomposição tem-se o terceiro incluído (sistema a três) e na heterocomposição o terceiro excluído (sistema com terceiro), enquanto a composição ignoraria a posição do terceiro quanto ao seu poder decisório ou não, uma vez que não distingue-se em "auto" ou "hetero".

\section{REFERÊNCIAS BIBLIOGRÁFICAS:}

ARISTÓTELES. Política: livro II. In: MORRIS, Clarence (Org.). Os grandes filósofos do Direito. São Paulo: Martins Fontes, 2002.

AUTOCOMPOSIÇÃO. In: Dicionário Priberam da Língua Portuguesa, 2008-2013.

Disponível em: https://www.priberam.pt/dlpo/autocomposi\%C3\%A7\%C3\%A3o. Acesso em: 18 set. 2017.

AUTOCOMPOSIÇÃO. In: Dicionário online de Português, 2009-2017. Disponível em: https://www.dicio.com.br/autocomposicao/. Acesso em: 18 set. 2017.

AUTOCOMPOSIÇÃO. In: Dicionário Brasileiro da Língua Portuguesa Michaelis. São

Paulo: Melhoramentos, 2017. Disponível em: http://michaelis.uol.com.br/modernoportugues/busca/portugues-brasileiro/autocomposi\%C3\%A7\%C3\%A3o/. Acesso em:

18 set. 2017.

\footnotetext{
${ }^{75}$ Esclarece-se que na arbitragem, apesar desta possuir uma origem democrática, a decisão final advém de um terceiro e, salvo tratar-se de sentença arbitral nula, esta se torna irrecorrível.
} 
Revista Eletrônica de Direito Processual - REDP.

Rio de Janeiro. Ano 11. Volume 18. Número 3. Setembro a Dezembro de 2017

Periódico Quadrimestral da Pós-Graduação Stricto Sensu em Direito Processual da UERJ

Patrono: José Carlos Barbosa Moreira. ISSN 1982-7636. pp. 69-93

www.redp.uerj.br

BATISTA JUNIOR, Onofre Alves. Transações administrativas. São Paulo: Quartier Latin, 2007.

BLANCHET, Luiz Alberto. A transparência na administração pública, o combate à

corrupção e os impactos no desenvolvimento. Revista do Direito, vol. 01, nº 51.

Santa Cruz do Sul, 2017.

BRASIL. Lei no 9.307 (1996). Brasília: Senado Federal, 23 set. 1996.

Código de Processo Civil (2015). Brasília: Senado Federal, 2015.

Lei no 13.140 (2015). Brasília: Senado Federal, 26 jun. 2015.

BOURDIEU, Pierre. O poder simbólico. Rio de Janeiro: Bertrand Brasil, 2005.

CALMON, Petrônio. Fundamentos da mediação e da conciliação. Brasília: Gazeta Jurídica, 2015.

CASTILLO, Niceto Alcalá Zamora y. Proceso, autocomposición y autodefensa. México:

Universidad Nacional Autónoma de México, 1991.

COMPOSIÇÃO. In: Dicionário Aurélio Online da Língua Portuguesa, 2016.

Disponível em: https://dicionariodoaurelio.com/composicao. Acesso em: 18 set. 2017.

COMPOSIÇÃO. In: Dicionário Priberam da Língua Portuguesa, 2008-2013.

Disponível em: https://www.priberam.pt/dlpo/composi\%C3\%A7\%C3\%A3o. Acesso em: 18 set. 2017.

COMPOSIÇÃO. In: Dicionário Brasileiro da Língua Portuguesa Michaelis. São Paulo:

Melhoramentos, 2017. Disponível em: http://michaelis.uol.com.br/modernoportugues/busca/portugues-brasileiro/composi\%C3\%A7\%C3\%A3o/. Acesso em: 18 set. 2017.

DAHRENDORF, Ralf. O conflito social moderno: um ensaio sobre a política da

liberdade. São Paulo: Jorge Zahar Editor, 1992.

DI PIETRO, Maria Sylvia Zanella. Direito administrativo. Rio de Janeiro: Forense, 2016.

FERRERIA, Aurélio Buarque de Holanda. Novo Aurélio Século XXI: o dicionário da língua portuguesa. Rio de Janeiro: Nova Fronteira, 1999.

GIRARD, Rene. Literatura, mimesis y antropologia. Barcelona: Gedisa, 1997.

GOLDBERG, B. et al. Dispute resolution: negotiation, mediation and other processes.

New York: Aspen Publishers, 2007. 
Revista Eletrônica de Direito Processual - REDP.

Rio de Janeiro. Ano 11. Volume 18. Número 3. Setembro a Dezembro de 2017

Periódico Quadrimestral da Pós-Graduação Stricto Sensu em Direito Processual da UERJ

Patrono: José Carlos Barbosa Moreira. ISSN 1982-7636. pp. 69-93

www.redp.uerj.br

HETEROCOMPOSIÇÃO. In: Dicionário Priberam da Língua Portuguesa, 2008-2013.

Disponível em: https://www.priberam.pt/dlpo/heterocomposi\%C3\%A7\%C3\%A3o. Acesso em: 18 set. 2017.

HETERO. In: Dicionário Priberam da Língua Portuguesa, 2008-2013. Disponível em: https://www.priberam.pt/dlpo/hetero-. Acesso em: 18 set. 2017.

MARX, Karl. O capital. O rendimento e suas fontes. São Paulo: Nova cultura, 1996.

MELLO, Maria Chaves de. Dicionário jurídico português-inglês. São Paulo: Método, 2006.

MULLER, Jean-Marie. O princípio da não-violência: percurso filosófico. Tradução de Maria Fernanda Oliveira. Lisboa: Instituto Piaget: 1995.

PINHO, Humberto Dalla Bernardina de; ALVES; Tatiana Machado. A cooperação no novo código de processo civil: desafios concretos para sua implementação. Revista

Eletrônica de Direito Processual. Rio de Janeiro, vol. 15, n. 15, 2015.

RISKIN, Leonard. Compreendendo as orientações, estratégias e técnicas do mediador: um padrão para perplexos. In: AZEVEDO, André Gomma de (org.). Estudos em arbitragem, mediação e negociação. Brasília: Brasília Jurídica, 2002. Disponível em: http://www.ipea.

gov.br/ouvidoria/images/stories/pdf/mediacao_negociacao_volume1.pdf. Acesso em: 15 set. 2017.

SIDOU, J. M. Othon (org.). Dicionário jurídico. Rio de Janeiro: Forense Universitária, 1991.

SILVA, Érica Barbosa e. Conciliação judicial. Brasília: Gazeta Jurídica, 2013.

SPENGLER, Fabiana Marion. Da jurisdição à mediação: por uma outra cultura no tratamento de conflitos. Ijuí: Editora Unijuí, 2010, p. 248.

. Uma relação à três: o papel político e sociológico do terceiro no tratamento dos conflitos. Revista Dados, vol. 59, nº 2. Rio de Janeiro abr./jun., 2016.

Mediação de conflitos: da teoria à prática. Porto Alegre: Livraria do Advogado, 2017.

WAMBIER, Luiz Rodrigues; TALAMINI, Eduardo. Curso avançado de processo civil: teoria geral do processo. São Paulo: Editora Revista dos Tribunais, 2016a. 
Revista Eletrônica de Direito Processual - REDP.

Rio de Janeiro. Ano 11. Volume 18. Número 3. Setembro a Dezembro de 2017

Periódico Quadrimestral da Pós-Graduação Stricto Sensu em Direito Processual da UERJ

Patrono: José Carlos Barbosa Moreira. ISSN 1982-7636. pp. 69-93

www.redp.uerj.br

WAMBIER, Luiz Rodrigues; TALAMINI, Eduardo. Curso avançado de processo civil:

cognição jurisdicional (processo comum de conhecimento e tutela provisória). São

Paulo: Editora Revista dos Tribunais, 2016b.

WEBER, Max. Economia e sociedade. Fundamentos da sociologia compreensiva.

Brasília: UNB, 1999.

\section{ANEXO I}

Figura 1:

\begin{tabular}{|l|l|l|}
\hline AUTOTUTELA & $\begin{array}{l}\text { Um dos envolvidos é o } \\
\text { responsável }\end{array}$ & Através da imposição \\
\hline AUTOCOMPOSIÇÃO & $\begin{array}{l}\text { Os envolvidos são os } \\
\text { responsáveis }\end{array}$ & Utiliza-se o consenso \\
\hline HETEROCOMPOSIÇÃO & $\begin{array}{l}\text { Existe um terceiro imparcial } \\
\text { responsável pela decisão }\end{array}$ & $\begin{array}{l}\text { A decisão é imposta aos } \\
\text { envolvidos }\end{array}$ \\
\hline
\end{tabular}

